\title{
Macrothink
}

\section{Research on Minority College Students' Engagement in English Learning}

\author{
Li Sun (corresponding author) \\ School of Foreign Languages, Nanyang Institute of Technology \\ No. 80 Changjiang Road, Nanyang 473004, China \\ E-mail: sunli_lizhi@163.com
}

Received: April 1, $2021 \quad$ Accepted: April 21, $2021 \quad$ Published: April 30, 2021

doi:10.5296/ijld.v11i2.18580 URL: https://doi.org/10.5296/ijld.v11i2.18580

\begin{abstract}
This paper studies the relationship between minority college students' English learning autonomy, English learning self-efficacy and English learning engagement, based on attribution theory and social cognitive theory. A questionnaire was first conducted on 570 ethnic minority non-English major college students in Yunnan province, Guizhou province, and Sichuan province, China. Then, statistical software is used to make regression analysis on the relationship between variables. Research results show that English learning autonomy has a significant positive impact on English learning engagement; English learning autonomy has a significant positive impact on English learning self-efficacy; English learning self-efficacy has a significant positive impact on English learning engagement; English learning self-efficacy has a partial mediating role in English learning autonomy and English learning engagement. Finally, some strategies are proposed to improve English learning engagement from motivation-driven perspective, involving learning evaluation, learning resources and learning guidance.
\end{abstract}

Keywords: minority college students; English learning engagement; English learning autonomy; English learning self-efficacy

\section{Introduction}

With the advancement of the "Belt and Road" initiative, China has had more investment and trade cooperation with countries along the "Belt and Road", which has promoted a new pattern of opening up to the outside world in ethnic minority areas. The "Silk Road Economic Belt" covers areas inhabited by ethnic minorities in Xinjiang, Qinghai, Ningxia, Gansu, Sichuan, Yunnan, and Guangxi. English is international universal language, and has been widely used in international political, economic and cultural exchange activities. However, 
due to the limitation of the economic development level, the education level of ethnic minority areas is lower than that of economically developed areas, and educational resources are relatively insufficient. In particular, English education started late, and the available educational resources are more limited (Geng, 2018). In addition, due to the low demand for English in job selection, minority college students lack English learning motivation (Li, 2018). As a unified multi-ethnic country, Chinese government has always attached great importance to the development of ethnic minority education. Minority college students bear the historical responsibility of carrying forward their own traditional cultures. Many scholars have verified the positive impact of students' engagement on student success and development (Villiers \& Werner, 2018; Wang, 2019; Sun et al., 2020). Therefore, this paper aims to study minority students' engagement in English learning and the factors that influence their learning engagement.

\section{Literature Review}

\subsection{Learning Engagement}

Since the 1990s, "student engagement" has attracted considerable attention in the education field and has become the latest focus to improve the quality of higher education teaching. Astin (1984) defined student engagement as "the quantity and quality of physical and mental energy students engage in college life" and stated that there is a positive correlation between college students' engagement and personal and academic growth. Schaufeli et al. (2002) defined engagement as a more persistent and pervasive affective-cognitive state, which is characterized by vigor, dedication and absorption. In the student version of work engagement. Vigor refers to high levels of energy and mental resilience while studying, the willingness to invest effort in one's work, and persistence even in the face of difficulties. Dedication refers to being strongly involved in one's study and experiencing a sense of significance, enthusiasm, inspiration, pride, and challenge. Absorption is characterized by being fully concentrated and happily engrossed in one's work and being difficult to detach oneself from study. Fredericks et al. (2004) defined student engagement as a multi-dimensional structure that includes behavioral engagement, emotional engagement and cognitive engagement. Behavioral engagement is the participation in academic activities, social activities and extracurricular activities, and it is essential to form a positive learning effect. Emotional engagement is the student's identification with the school, including the sense of belonging and the awareness of the school's success. Cognitive engagement is the degree of student's investment in learning, which refers to the necessary effort to understand complex ideas or master difficult skills through thoughtful, strategic, and active efforts. Chinese scholar Wen et al. (2014) stated that the effect of learning engagement depends on the active input of students, the environmental support provided by the school, and the interaction between the individual and the school. Wang (2015) described that learning engagement includes students' active learning, student-teacher interaction, students' deep cognition, and learning enthusiasm. Fan (2019) put forward the dimension of social engagement in the study of online learning engagement. Social engagement refers to the learner's interaction with resources and other learners, such as participating in learning discussions, helping other students, etc. 


\subsection{Learning Autonomy}

Among the studies that use modern language teaching to explain learner autonomy, Holec's (1981) definition of learner autonomy has been widely recognized. He defined learner autonomy as "the ability to be responsible for one's own learning", which is the ability to be responsible for one's own learning in a language learning environment, to actively choose learning content and learning methods, and to evaluate one's own learning progress. Besides, autonomous learning emphasizes the student-oriented learning method, which reflects the subjectivity of students. Chinese scholar Zhou (2016) stated that student autonomy is a kind of internal mechanism that dominates individual learning behavior, which is composed of students' cognitive level, emotional attitude and actual behavior. The author divided learning autonomy into three dimensions: cognitive autonomy, emotional autonomy and behavioral autonomy. Cognitive autonomy means that students have a general understanding of their own learning processing, activities, and tasks, and manage their own learning in real time and make corresponding adjustments based on feedback. Emotional autonomy refers to the degree of academic motivation after perceiving learning tasks. When external or internal incentives stimulate individuals to generate learning motivation, students will have a tendency to learn and show a series of behaviors related to autonomous learning. Behavioral autonomy refers to a series of practical behaviors in which an individual actively and effectively conducts learning on a voluntary basis. Duan (2019) also stated that learning autonomy means that in the learning process, learners can determine their goals according to their own wishes and abilities, choose learning materials according to their own needs, and adopt their own methods to monitor and evaluate the learning process. However, Chinese scholar Chai (2016) pointed out that independence in learning autonomy does not mean to completely separate from others, and proper other-oriented learning can generate positive autonomous learning effects. The training and guidance of teachers on learning methods will promote students to learn how to study independently.

\subsection{Learning Self-Efficacy}

According to Bandura's social cognitive theory (1977), self-efficacy is a positive emotion, a belief that one has the ability to complete a learning task. According to Heider's attribution theory (1958), people's attribution to an event depends on whether the causal trajectory of the event is internal or external. The internal trajectory consists of two parts: motivation and ability. External trajectory refers to external environmental factors, not human factors. Therefore, when the learner perceives that success comes from personal ability, the sense of self-efficacy will increase when they succeed. On the contrary, when a person feels unable to actively control the cause of the event, there will be a sense of shame and self-efficacy will be weakened. It can be seen that people with high self-efficacy usually think that they can control their lives, and that their own actions and decisions will affect their lives, while people with low self-efficacy think that they cannot control their lives. Kong (2019) defined learning self-efficacy as an individual's judgment and self-confidence in his ability to successfully complete academic tasks, including self-efficacy of learning competence and self-efficacy of learning ability. The former refers to an individual's assessment of whether they are capable of completing their studies, achieving good grades and avoiding academic 


\section{Macrothink}

failures; the latter refers to students' assessment of whether they can adopt learning behaviors to achieve their learning goals. Therefore, People with a higher sense of self-efficacy are more likely to view difficult tasks as something to master rather than something to avoid. People with a higher sense of self-efficacy are more likely to believe that they can solve challenging problems and recover quickly from setbacks and disappointments. On the contrary, people with lower self-efficacy will lack self-confidence, think that they are not competent at work, and will avoid dealing with challenging work tasks.

\subsection{Relationship between Learning Autonomy, Self-efficacy and Learning Engagement}

Highly engaged students focus their energy on learning, attend class on time, observe class discipline, concentrate, persevere when encountering difficulties, use effective learning strategies, and form a positive emotional experience and a sense of belonging (Wellborn,1991). Autonomous learning requires students to look up the materials themselves and achieve learning tasks, which can examine the students' autonomous academic motivation. The degree of English autonomous learning motivation is an important criterion for judging student's English learning engagement (Shang, 2020). Besides, the success of students' English learning depends on regulation. External regulation refers to the regulation of students by society, schools, parents, and teachers, and internal regulation refers to students' self-regulation (Zhao, 2019). Autonomous learning ability is not an innate ability, but an ability that needs to be cultivated and improved. Teachers' academic support is helpful to improve college students' English autonomous learning ability (Liang, 2017). Students with a high sense of self-efficacy have the belief that they have the ability to learn English well and are willing to devote more time to English learning, and regard the difficulties encountered in learning as meaningful challenges and quickly recover from mental exhaustion (Zhu, 2020). Based on the above review, this article proposes four hypotheses:

Hypothesis 1: English learning autonomy has a positive impact on English learning engagement.

Hypothesis 2: English learning autonomy has a positive impact on English learning self-efficacy.

Hypothesis 3: English learning self-efficacy has a positive impact on English learning engagement.

Hypothesis 4: English learning self-efficacy has a mediating role between English learning autonomy and English learning engagement. 


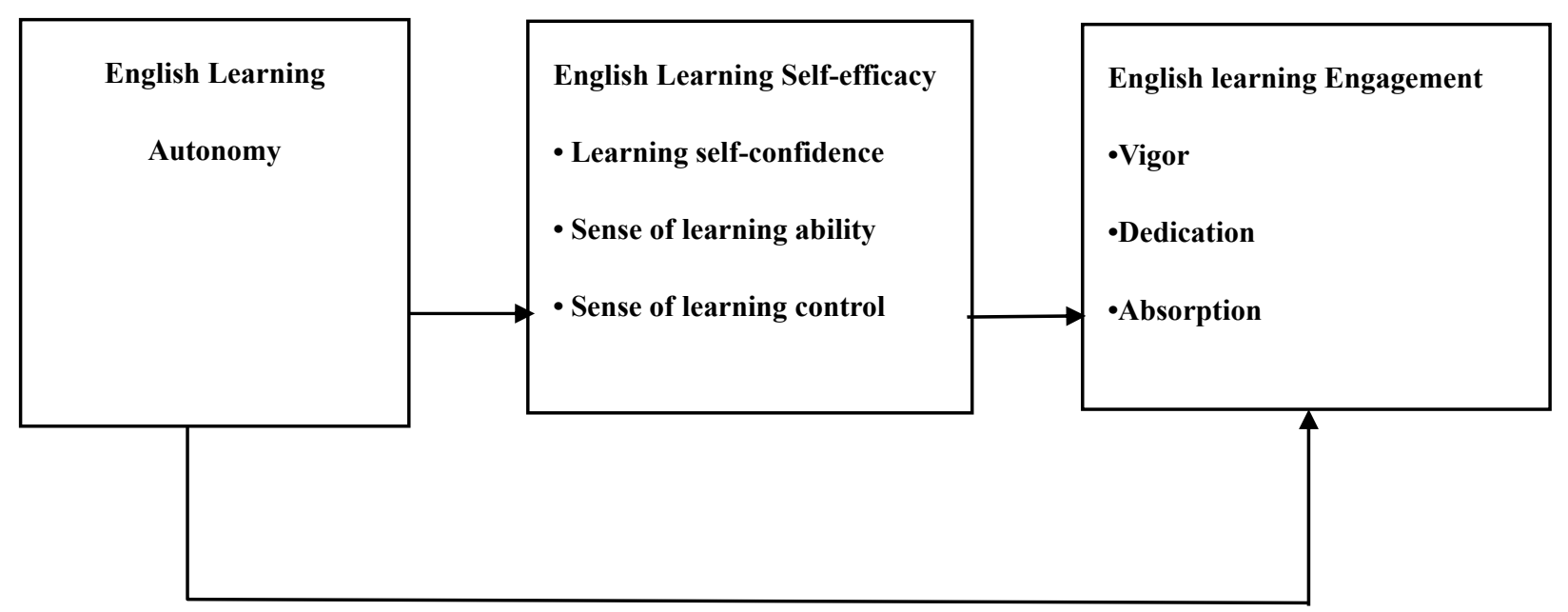

Figure 1. conceptual framework

\section{Methodology}

\subsection{Population and Sample}

China's ethnic minorities are mainly distributed in border areas such as the southwest, northwest, and northeast. Among them, Yunnan, Guizhou, and Sichuan provinces in the southwest are the areas where ethnic minorities live most in China. According to official statistical reports, as of the end of 2019, the ethnic minority populations in Yunnan, Guizhou, and Sichuan provinces were respectively 16,2126 million, 12.8227 million, and 5.994 million. As of June 30, 2020, there are 132 colleges and universities in Sichuan Province, 75 colleges and universities in Guizhou Province, and 82 colleges and universities in Yunnan Province. Besides, Chinese non-English majors generally learn English for two years. Therefore, this article takes first-year and second-year college students of minority non-English majors from universities in Yunnan, Guizhou, and Sichuan provinces as survey population. A total of 585 questionnaires were received in this survey. Questionnaires with the same options for all or most of the questions, and questionnaires with too short response time were considered invalid questionnaires. Finally, 570 questionnaires were determined to be valid questionnaires, with an effective rate of $97 \%$.

\subsection{Questionnaire Design}

The questionnaire consists of four parts. The first part is the gender, grade, and discipline category of respondents; the second part is the English learning engagement scale, which is adapted from Schaufeli et al. (2002) student engagement scale, which is a three-factor model, and its Cronbach's a is 0.84 . This scale also has been verified to have a good reliability and validity within Chinese culture context (Wang, 2018). In order to ensure students to have a better understanding of the questionnaire content, the researcher translated original English questionnaire into Chinese, then asked a college English teacher to translate Chinese version back into English, then compare the consistency of the two English versions. Finally, the 


\section{1ll Macrothink}

International Journal of Learning and Development

ISSN 2164-4063

2021, Vol. 11, No. 2

researcher discussed with two Chinese experts in Management about the questionnaire's words and expressions and do a small amount of pre-test, finally make some adjustments to the language of Chinese version of learning engagement scale. The third part is the English learning self-efficacy scale, from Chinese scholar Li et al. (2006) English learning self-efficacy scale, which contains three dimensions of self-confidence in learning, sense of learning ability, sense of learning control. The authors have proved that the Cronbach's alpha coefficient of the questionnaire is 0.836. The fourth part is the English learning autonomy scale, adopted 7 items from Lv (2014)'s Autonomous English Learning Questionnaire, involving students' choice of learning content, learning methods, and self-evaluation. The measurement form is the Likert 5-point scale, 1 represents "strongly incompatible", 2 represents "incompatible", 3 represents "unclear", 4 represents "compatible", and 5 represents "strongly compatible".

\subsection{Data Collection and Analysis}

This study adopts purpose sampling through online questionnaire survey. The researcher first contacted teachers working in colleges and universities in Yunnan, Guizhou, and Sichuan, and entrusted them to choose non-English majors in the university to complete the questionnaire. At the same time, the researcher entrusted the college students who participated in the questionnaire to help recommend other minority college students who meet the research standards to do the survey questionnaire. Reliability analysis and regression analysis are used to test the reliability of adopted scales and the causal relationship between variables.

\section{Research results}

\subsection{Reliability Analysis}

The reliability test shows that English learning engagement scale, English learning self-efficacy scale, and English learning autonomy scale have high internal consistency and are acceptable, because their Cronbach's a coefficient are all greater than 0.9. This also shows that the three scales are applicable to the English learning measurement of Chinese ethnic minority college students (Table 1).

Table 1. Reliability Analysis (N=570)

\begin{tabular}{llc}
\hline Variable & Cronbach’s Alpha & Item \\
\hline English Learning Engagement (LE) & 0.989 & 17 \\
English Learning Self-efficacy (LS) & 0.980 & 20 \\
English Learning Autonomy (LA) & 0.977 & 7 \\
\hline
\end{tabular}


4.2 The Influence of English Learning Autonomy on English Learning Engagement

According to the results of linear regression analysis, English learning autonomy has a significant positive impact on English learning engagement (Beta=0.983, $\mathrm{P}=0.000$ ), indicating that the stronger the student's English learning ability, the higher the degree of English learning engagement. The regression model has a good fitting effect (Adjusted R-square=0.966), and English learning autonomy explains 96.6\% of English learning engagement (Table 2).

Table 2. Regression analysis of English learning autonomy on English learning engagement $(\mathrm{N}=570)$

\begin{tabular}{|c|c|c|c|c|c|c|c|}
\hline \multirow[t]{2}{*}{ Model } & \multicolumn{2}{|c|}{ Variable } & \multicolumn{2}{|c|}{ Unstandardized } & \multicolumn{3}{|c|}{ Standardized } \\
\hline & & & B & Std. Error & Beta & $\mathrm{t}$ & Sig. \\
\hline & (Cons & ant) & .283 & .027 & & 10.562 & .000 \\
\hline & LA & & .884 & .007 & .983 & 127.848 & .000 \\
\hline \multirow{3}{*}{\multicolumn{2}{|c|}{ Model Summary }} & Adjusted R-square & & & \multicolumn{2}{|c|}{.966} & \\
\hline & & Sig. F & & & \multicolumn{2}{|c|}{$.000 * * *$} & \\
\hline & & Change & & & & & \\
\hline
\end{tabular}

Note. Dependent Variable: LE; *** indicates significant at 0.001 level (2-tailed test).

\subsection{The Influence of English Learning Autonomy on English Learning Self-efficacy}

According to the results of linear regression analysis, English learning autonomy has a significant positive impact on English learning self-efficacy (Beta=0.983, $\mathrm{P}=0.000$ ), indicating that the stronger the student's English learning ability, the higher the degree of English learning self-efficacy. The regression model has a good fitting effect (Adjusted R-square=0.967), and English learning autonomy explains 96.7\% of English learning self-efficacy (Table 3). 
Table 3. Regression analysis of English learning autonomy on English learning self-efficacy $(\mathrm{N}=570)$

\begin{tabular}{|c|c|c|c|c|c|c|c|}
\hline \multirow[b]{2}{*}{ Model } & \multirow{2}{*}{\multicolumn{2}{|c|}{ Variable }} & \multicolumn{2}{|c|}{ Unstandardized } & \multicolumn{3}{|c|}{ Standardized } \\
\hline & & & B & Std. Error & Beta & $\mathrm{t}$ & Sig. \\
\hline & (Const & int) & .705 & .025 & & 27.682 & .000 \\
\hline & LA & & .851 & .007 & .983 & 129.511 & .000 \\
\hline \multirow{3}{*}{\multicolumn{2}{|c|}{ Model Summary }} & Adjusted R-square & & & \multicolumn{2}{|c|}{.967} & \\
\hline & & Sig. F & & & \multicolumn{2}{|c|}{$.000 * * *$} & \\
\hline & & Change & & & & & \\
\hline
\end{tabular}

Note. Dependent Variable: LS; *** indicates significant at 0.001 level (2-tailed test).

\subsection{The Influence of English Learning Self-efficacy on English Learning Engagement}

According to the results of linear regression analysis, English learning self-efficacy has a significant positive impact on English learning engagement (Beta=0.991, $\mathrm{P}=0.000$ ), indicating that the stronger the student's English learning self-efficacy, the higher the degree of English learning engagement. The regression model has a good fitting effect (Adjusted R-square $=0.981$ ), and English learning self-efficacy explains 98.1\% of English learning engagement (Table 4).

Table 4. Regression analysis of English learning self-efficacy on English learning engagement $(\mathrm{N}=570)$

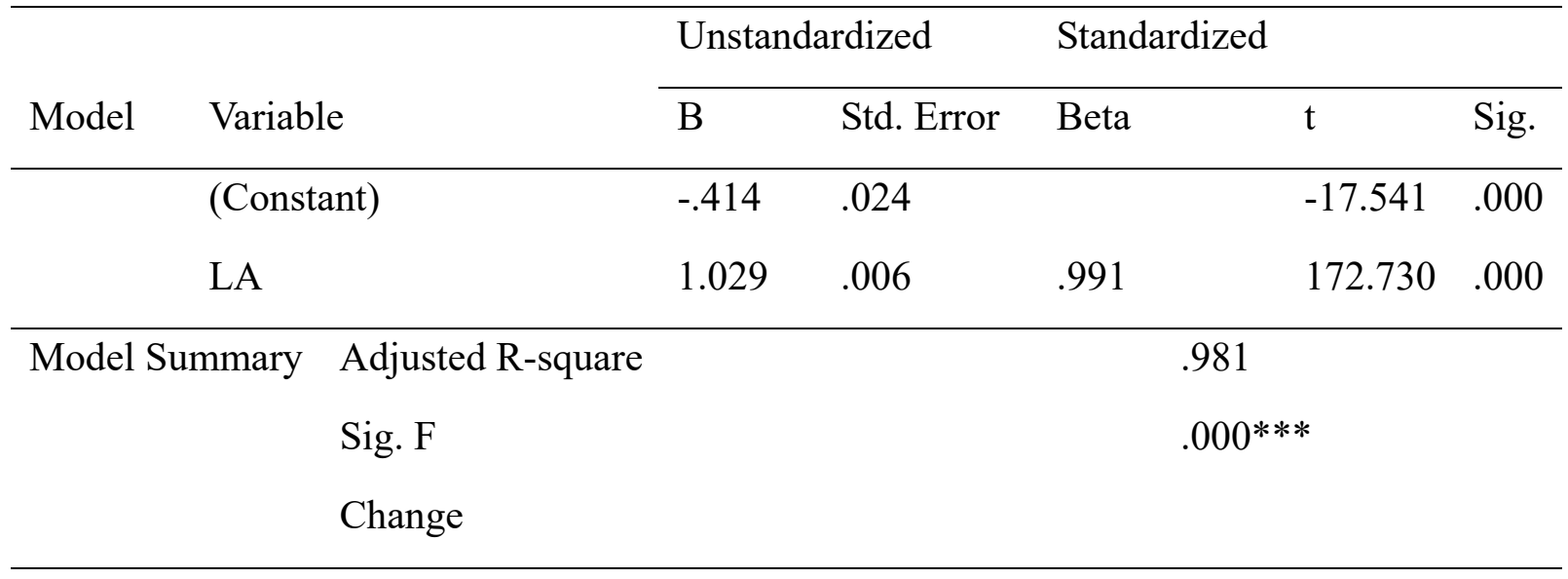

Note. Dependent Variable: LE; $* * *$ indicates significant at 0.001 level (2-tailed test).

\subsection{The Mediating Effect of English Learning Self-Efficacy}


In research hypotheses the independent variable is English learning autonomy, the dependent variable is English learning engagement, and the mediating variable is English learning self-efficacy. In order to test the mediating effect of English learning self-efficacy, the three variables are first centralized, and then linear regression analysis is used to test the total effect of the LA on LE. The total effect is significant (Beta $=0.983, \mathrm{P}=0.000$. The direct effect of LA on LZ after adding mediating variable on the dependent variable is also significant (Beta $=0.269, \mathrm{P}=0.000$ ), indicating that English learning self-efficacy plays a partially mediating role between English learning autonomy and English learning engagement (Table $5)$.

Table 5. Analysis of the mediating effect of English learning self-efficacy $(\mathrm{N}=570)$

\begin{tabular}{|c|c|c|c|c|c|c|}
\hline \multirow[b]{2}{*}{ Model } & \multirow[b]{2}{*}{ Variable } & \multicolumn{2}{|l|}{ Unstandardized } & \multicolumn{3}{|c|}{ Standardized } \\
\hline & & B & Std. Error & Beta & $\mathrm{t}$ & Sig. \\
\hline & (Constant) & -2.711 & .010 & & -.003 & .998 \\
\hline \multirow[t]{5}{*}{1} & C-LA & .884 & .007 & .983 & 127.848 & .000 \\
\hline & Model & Adjusted & & & .966 & \\
\hline & Summary & R-square & & & & \\
\hline & & Sig. F Change & & & .000 & \\
\hline & (Constant) & -1.181 & .010 & & -.001 & .999 \\
\hline \multirow[t]{5}{*}{2} & C-LA & .851 & .007 & .983 & 129.511 & .000 \\
\hline & Model & Adjusted & & & .967 & \\
\hline & Summary & R-square & & & & \\
\hline & & Sig. F Change & & & .000 & \\
\hline & (Constant) & -1.820 & .007 & & -0.003 & .998 \\
\hline \multirow[t]{5}{*}{3} & C-LA & .242 & .027 & .269 & 9.074 & .000 \\
\hline & C-LS & .754 & .031 & .726 & 24.500 & .000 \\
\hline & Model & Adjusted & & & .984 & \\
\hline & Summary & R-square & & & & \\
\hline & & Sig. F Change & & & .000 & \\
\hline
\end{tabular}

Note. Model 1 Dependent Variable $=\mathrm{C}-\mathrm{LE}$, Model 2 Dependent Variable $=\mathrm{C}-\mathrm{LS}$, Model 3Dependent Variable $=\mathrm{C}-\mathrm{LE} ; * * *$ indicates significant at 0.001 level (2-tailed test). 
It can be seen from the table 5 that the mediating effect of English learning self-efficacy plays partial mediating effect, and the influence of English learning autonomy on English learning engagement is not completely affected by the mediating effect of English learning self-efficacy. English learning autonomy has a partial direct impact on English learning engagement. The mediating effect of English learning self-efficacy has a greater contribution to the total effect of English learning autonomy on English learning engagement, about $72.6 \%$, and $13.4 \%$ of learning engagement change can be explained by the mediation effect. Therefore, English learning self-efficacy plays an important role in promoting the positive influence of English learning autonomy on English learning engagement.

\section{Conclusion}

\subsection{Discussion}

Research results show that all the four hypotheses are accepted. English learning autonomy has a significant positive impact on English learning engagement. English learning autonomy has a significant positive impact on English learning self-efficacy. English Learning self-efficacy has a significant positive impact on English learning engagement. English learning self-efficacy has a partial mediating role in the relationship between English learning autonomy and English learning engagement. It can be seen that autonomous learning ability is an important indicator for evaluating students' engagement in English learning process, reflecting their ability to regulate learning, and affects their confidence in English learning ability. Motivation is important in requiring students to be responsible for their own learning. Learning self-efficacy is the belief that students believe that they can complete their learning tasks, and it's an internal motivation to stimulate learners to study hard. The development of students' intrinsic motivation has always been considered the key to an effective teaching system, especially when the interaction environment between teachers and students is limited. If students are highly motivated to learn, they will study hard in the process of autonomous learning. Even if they encounter difficulties, they will adjust their negative emotions, restore confidence in their own learning ability, and invest more time and energy to improve English learning performance.

\subsection{Suggestions}

\subsubsection{Standardize the Evaluation Method of English Autonomous Learning}

The learner's autonomy reflects the ability to be responsible for their own learning, which embodies the humanistic thinking, and centers on the learner's inner world, individual thinking, willingness and emotional development. As representative scholars of humanism, Abraham Maslow and Carl Rogers emphasize the "individual learner" as the center. They believe that learning is not only intelligence, but also the education of the "whole person". Individual interests, goals and enthusiasm must be taken into account in order to be realize his potential. It can be seen that the humanistic learning method is student-centered and encourages learners to be responsible for their own learning out of internal motivation. At present, the college English teaching philosophy of various minority colleges is changing to a humanistic education view. The selection of college English course materials and the 
formulation of the syllabus are closely centered on the training goals of comprehensive English language skills and autonomous learning ability. In order to cultivate students' awareness of autonomous learning, English teachers assign assignments to students, allowing students to use the learning content in class or look up online information to complete learning tasks after class. Various college English textbooks also choose topics that are closely related to the personality development of college students, and each unit retains the content of self-study. In addition, some minority college teachers use the online teaching platform to assign autonomous learning tasks to students. However, these learning tasks are arranged to students from the teacher's point of view, without asking for students' ideas and opinions. In this way, students will be unable to clarify their learning goals, but passively follow the teacher's requirements. It is difficult to stimulate students' intrinsic motivation and may finally lead to learning burnout. Therefore, universities and colleges can start with the assessment method of college English courses and integrate the effect of English autonomous learning into the final assessment of the course.

Teachers can establish autonomous learning personal files for students and use a combination of student self-evaluation and teacher evaluation to score students' autonomous learning ability. Specifically speaking, the process assessment should delete the various language skills training tasks assigned by the teacher, leave more time for students to think and formulate their own English learning goals and learning plans, and use learning platform to choose appropriate learning content under the guidance of the teacher, self-track learning progress and test learning effects, and write an English learning summary at the end of the semester including personal learning goals, learning plans, achievements, problems, analysis of reasons, improvement measures. This not only allows students to fully understand their own strengths and weaknesses in the learning process, and let students know the way they are working hard, but also provides teachers with precious teaching suggestions, which is conducive to teachers' personalized guidance on students' English learning. The method of teacher evaluation is still based on the students' pre-class preview and after-class review as the main evaluation indicators. Teachers can check students' notebooks and class performance, keep evaluation sheet to the individual learning file. The archiving of individual self-study situations is conducive to teachers' systematic evaluation of students' English learning, and it is also conducive to the follow-up investigation of students' English proficiency during college, discovering deep-seated reasons that affect the English learning level of non-English major minority college students, and promoting planning for English teaching and management.

\subsubsection{Develop School-Based English Self-Learning Resource Library}

As a highly applied discipline, English has strict requirements on the language learning environment and learning content. Autonomous study is an important way to improve the quality of learning, and it is also a key factor to increase the degree of learning engagement. If there is a lack of an autonomous learning environment and abundant learning resources, even if students have the idea of learning English well, they cannot put them into action, which will dampen their interest in learning English. At present, the autonomous learning of many ethnic minority college students is mainly completed in a few fixed multimedia 
computer rooms. Although colleges and universities provide students with a place for autonomous learning, the number of non-English majors is large, the number of autonomous learning classrooms is small, the opening hours are limited. The lack of teacher support services also makes it difficult to solve the problems encountered in autonomous learning in a time, thereby affecting the effect of English learning and training of autonomous learning ability. Therefore, ethnic minority colleges and universities should use the existing resource platform of the library to develop a school-based college English online learning resource library, so that college students can use the mobile APP to make ubiquitous English learning and use the school's digital library resources to inquire about the e-books, newspapers, papers, audio and video resources, and borrow the materials according to the coding of the literature materials. When students search for learning materials on the library learning platform, the platform can also automatically recommend related series of learning materials for students' reference based on personal search records. In terms of developing online English course resources, for sake of examination. English teachers can upload test materials of different difficulty levels about listening, speaking, reading, writing, and translation and provide answers and explanations. For sake of communicative competence, English teachers can upload learning materials of Chinese and Western cultures to enhance students' sensitivity to cultural differences; for sake of critical thinking skills, English teachers can recommend authoritative domestic English learning platform, such as CGTN, China Daily, etc.

CGTN is a news channel of China International Television Station. The program is very rich in content, including global news, domestic news, interviews with people, Chinese cultural stories and other programs. It is a good English listening practice material, allowing students to learn about the world while practicing listening and learn to tell Chinese stories in English. China Daily is an authoritative website that disseminates Chinese information to the world. The content of news reports is comprehensive, and the English expression is accurate. It allows students to read the latest daily news content and keep abreast of major events in China and the world. The bilingual reading content of the China Daily website is rich, which can expand students' English vocabulary and improve the accuracy of words used in students' English expressions. Bilingual reading column can also help students think about the differences in language expressions between Chinese and English, master Chinese-to-English translation skills to better propaganda Chinese culture.

\subsection{Provide Minority English Academic Advisor}

In the process of learning English, ethnic minority college students often need to understand some English language expressions in a specific Western cultural background. According to the language characteristics of ethnic minorities, the school should focus on talent cultivation of cross-cultural communicative competence and select full-time teachers from ethnic minorities who know Chinese, ethnic language and English as English academic advisors for ethnic minority college students. They are familiar with the ethnic culture and have the high level of English, which makes it easy to integrate into the psychological world of ethnic minority college students and encourage ethnic minority college students to believe that they can learn English well. The cooperation in trade, culture, tourism, and infrastructure construction between ethnic minority areas and countries along the "Belt and Road" urgently 
needs interdisciplinary professionals who understand foreign languages, culture, and trade. Therefore, academic advisors can assign English extracurricular reading tasks to ethnic minority college students, allowing students to read social and cultural books about English-speaking countries, expand their English vocabulary, and enhance their ability to use English language accurately. Then academic advisors ask minority students to learn the society and culture of Southeast Asian countries based on geographical advantages, thereby improve the ability to serve international business and cultural exchange activities in English. At present, China's ethnic minority areas and Southeast Asian countries have many cultural exchanges and cooperation. Many ethnic college students have the chance to study in Southeast Asian countries through Chinese-foreign cooperation model in running schools. As international students, their course learning and academic exchanges are still mainly in English, which require solid English language skills. Therefore, the study of the culture of English-speaking countries and Southeast Asian countries can not only stimulate students' enthusiasm for learning English, but also enhance students' cross-cultural awareness, so that students can learn to understand different behaviors from different cultural perspectives, avoid cross-cultural communication conflicts, and achieve effective input of foreign culture and output of Chinese culture.

Students will encounter difficulties and feel frustrated in the process of English autonomous learning, such as being unable to understand English articles due to too many new words, too complicated sentence structure, fast speed of the English news reports, resulting in emotional exhaustion and loss of interest in learning English. Therefore, academic advisors should be concerned about the students' state of mind, understand the students' confusion and the support they need in the process of learning English through individual conversations or questionnaires, and provide personalized psychological counseling and guidance to students. In order to increase students' self-efficacy, the academic advisor should break down the learning goals into small goals that can be completed in a short time. When the students complete the small goals, they will get a certain sense of accomplishment and believe in their learning ability. In addition, academic advisors should give affirmative evaluations when students make progress, so that students can feel the care and recognition of academic advisors, which in turn, motivate them study harder.

\section{References}

Astin, A. W. (1984). Student Involvement: A Developmental Theory for Higher Education. Journal of College Student Development, 40(5), 518-529.

Bandura, A. (1977). Self-efficacy: Toward a unifying theory of behavioral change. Psychological Review, 84(2), 191-215. https://doi.org/10.1037/0033-295X.84.2.191

Cheng, M. Q., Guo, R. X., An, H. Y., Wang, L. S., Pu, J. H., \& Wu, S. Y. (2019). Correlation analysis of academic self-efficacy and learning engagement of undergraduate nursing students. Health Vocational Education, 37(11), 137-139.

Chai, J. Y. (2016). Research on the development of student learning autonomy (Unpublished doctoral dissertation). East China Normal University, Shanghai. 
De Villiers, B., \& Werner, A. (2018). The relationship between student engagement and academic success. Journal for New Generation Sciences, 14(1), 36-50.

Duan, J. (2019). Research on college students' autonomous learning in the era of "fragmentation" (Unpublished master's thesis). Hunan University of Science and Technology, Xiangtan.

Fan, R. (2019). Research on strategies for improving online learning engagement (Unpublished master's thesis). Northwest Normal University, Lanzhou.

Fredricks, J. A., Blumenfeld P. C., \& Paris, A. H. (2004). School engagement: Potential of the concept, state of the evidence. Review of Educational Research, 74(1), 59-109. https://doi.org/10.3102/00346543074001059

Geng, X. (2018). Analysis on the English language competence of minority college students in local universities under the international environment. Guizhou Ethnic Studies, 39(10), 225-228. https://doi.org/10.13965/j.cnki.gzmzyj10026959.2018.10.050

Heider, F. (1958). The psychology of interpersonal relations. London: Lawrence Erlbaum Associates. https://doi.org/10.1037/10628-000

Holec, H. (1981). Autonomy and foreign language learning. Oxford: Pergamon.

Li, L., Chen, Z. A., \& Jiang, Y. H. (2006). Strategy-style-attribution: Learn English. Shanghai: Shanghai Foreign Language Education Press.

Liang, X. L. (2017). Effect of teacher support and peer support on learner autonomy of English Majors (Unpublished master's thesis). Xi'an International Studies University, Xi'an.

Li, Q. F. (2018). Research on the reform of English curriculum in ethic colleges based on MOOCS training. Guizhou Ethnic Studies, 39(7), 217-221. https://doi.org/10.13965/j.cnki.gzmzyj10026959.2018.07.049

Lv, S. (2014). An empirical study on college students' autonomous English learning and self-efficacy in content based instruction (Unpublished master's thesis). North University of China, Taiyuan.

Schaufeli, W. B., Salanova, M., González-romá, V., Bakker, A. B. (2002). The measurement of engagement and burnout: A two sample confirmatory factor analytic approach. Journal of Happiness Studies, 3, 71-92. https://doi.org/10.1023/A:1015630930326

Shang, J. G. (2020). College students' learning engagement in English and its influence factors. Journal of Tongling University, 19(6), 113-116.

Sun, S., Liu, X. C., Li, S. J., \& Song, M. (2020). The mediating role of learning engagement between academic motivation and academic achievement of medical students in a university in Xinjiang. Reform and Opening, 23 , 87-92. https://doi.org/10.16653/j.cnki.32-1034/f.2020.005-006.023

Wang, Y. S. (2015). An empirical study of the impact of the college students' engagement in 


\section{Macrothink}

International Journal of Learning and Development

ISSN 2164-4063 2021, Vol. 11, No. 2

learning and the outcomes. Journal of national academy of education administration, 7 , 76-81.

Wang, S. B. (2018). Study on the relationship of academic self-concept, social support and study engagement of college students (Unpublished master's thesis). Nanchang University, Nanchang.

Wang, S. L. (2019). The influence of learning engagement on undergraduates' learning effect and learning outcome. Journal of Jining University, 40(1), 91-98.

Wellborn, J. G. (1991). Engaged and disaffected action: The conceptualization and measurement of motivation in the academic domain (Unpublished doctoral dissertation). University of Rochester, New York.

Wen, W., Shi, J. H., \& Zhou, Z. J. (2014). The fourth-year undergraduate phenomenon: Transition of the learning style. Tsinghua journal of education, 35(3), 45-54+80. https://doi.org/10.14138/j.1001-4519.2014.03.021

Xiao, H. Y., Li, Y., Yan, Y. F., \& Fu, Z. (2020). The influence of academic self-efficacy on learning engagement. Journal of Shanxi Datong University (Natural Science), 36(1), 68-70.

Zhao, D. Y. (2019, July). Consciously accept teachers' guidance and strive to cultivate self-learning ability. (eds.) Proceedings of 2019 Forum of Fujian Business Association (pp.183-186). Xiamen, China: Fujian Business Association. https://doi.org/10.26914/c.cnkihy.2019.071573

Zhu, Y. Q. (2020). A study on the relationship between academic self-efficacy, learning input and academic achievement of undergraduates majoring in physical education (Unpublished master's thesis). Henan University, Kaifeng.

\section{Copyright Disclaimer}

Copyright for this article is retained by the author(s), with first publication rights granted to the journal.

This is an open-access article distributed under the terms and conditions of the Creative Commons Attribution license (http://creativecommons.org/licenses/by/4.0/). 